\title{
Early Arrest of Mental and Motor Development Associated with Bilateral Hippocampal Anoxic Damage
}

\author{
C.M. Fisher
}

\begin{abstract}
Background: Clinical-pathological study of the case of a woman with amentia from birth. Case history: A 45-year-old woman was institutionalized since the age of two and showed no change in 43 years. She did not stand, walk, talk, use her hands or comprehend. She was placed in a chair each day. She lacked control of bladder and bowel. She showed no mental capability. Case pathology: The brain weighed $1250 \mathrm{gm}$ and was normally developed. There were two anoxic-ischemic regions of damage. The hippocampus showed extensive damage bilaterally and the cerebellum showed watershed infarction bilaterally. Conclusion: A perinatal anoxic-ischemic episode is suspected. Hippocampal damage was the only finding that might explain the failure of mental and motor development. If this hypothesis is correct, the function of the human hippocampus is broader than currently accepted.
\end{abstract}

RÉSUMÉ: Arrêt précoce du développement mental et moteur associé à une atteinte anoxique bilatéral de l'hippocampe. Introduction: Il s'agit d'une observation clinique et anatomopathologique du cas d'une femme atteinte de déficience mentale depuis la naissance. Observation: Une femme âgée de 45 ans avait été placée en institution à l'âge de deux ans et son état n'avait pas changé en 43 ans. Elle ne pouvait pas se tenir debout, marcher, parler, utiliser ses mains et n'avait aucune compréhension. Elle demeurait assise dans une chaise toute la journée. Elle n'avait pas de contrôle sur sa vessie et ses intestins. Elle n'avait aucune capacité mentale. Anatomopathologie: Son cerveau pesait $1250 \mathrm{gm}$ et présentait un développement normal. Il existait deux régions présentant un dommage anoxique-ischémique. L'hippocampe présentait un dommage bilatéral important et le cervelet un infarctus bilatéral massif. Conclusion: Nous soupçonnons qu'un épisode anoxique-ischémique périnatal est responsable de ces lésions. La seule observation qui puisse expliquer l'absence de développement mental et moteur est le dommage à l'hippocampe. Si cette hypothèse est correcte, la fonction de l'hippocampe humain est plus vaste que ce qui est reconnu actuellement.

Can. J. Neurol. Sci. 2003; 30: 375-377

A 45-year-old caucasian woman, resident in a state institution for custodial care since the age of two, died of acute aspiration asphyxia, having been found dead in bed shortly after a meal.

She was admitted at the age of two years because of failure to thrive, delayed growth and mental retardation. She was the product of the 11th of 16 pregnancies, six of which terminated in the birth of premature infants who died in the first six to 12 months. A sibling was described as being in a state similar to the present patient and also resided in an institution.

In the span of 43 years, there had been no significant mental or motor development. She did not stand or walk. Each day she was placed in a chair with supports to keep her upright. She did not speak and showed no evidence of being aware of the attendants around her who regularly endeavored to elicit responses. She did not use her hands for feeding. She did not assist with feeding and required that food be placed in the back of her mouth. She gulped her food and regularly regurgitated. The only activity observed was the occasional nudge of a wooden block on the play-tray in front of her. This movement may well have been accidental. The only vocalization consisted of uninterpretable grunts associated with facial grimacing. She could move all limbs equally but moved little spontaneously. At one time she could rock in a rocking chair. She was incontinent of bladder and bowel.

Visual function was difficult to assess. She had an aversion to light and showed intact pupillary reflexes, intact ocular movements and a normal fundoscopic examination. There was no response to sound and it was concluded that she was deaf and mute. The tendon reflexes were symmetrically equal.

She had a poorly characterized seizure disorder, first noted several

From the Department of Neurology, Massachusetts General Hospital, Boston MA, USA.

Received March 10, 2003. AcCePtedin Finalform May 27, 2003. Reprint requests to: C.M Fisher, Department of Neurology, Massachusetts General Hospital, Fruit Street, Boston MA02114 USA 
days before her first admission, when a tonic-clonic seizure followed by postictal depression was observed. She was treated with dilantin without further seizure activity. There were no focal electroencephalographic abnormalities.

For several months there had been increasing difficulty with feeding and multiple episodes of aspiration occurred associated with X-ray evidence of interstitial pneumonitis.

Her growth over the years was described as remarkably retarded but on postmortem examination her height was $140 \mathrm{~cm}$ and her weight $100 \mathrm{lbs}$.

\section{Pathological examination}

The cause of death was asphyxia due to meat lodged in the pharynx. The lungs showed chronic lipoid pneumonia, possibly the result of chronic aspiration. There were no congenital abnormalities of viscera or the rest of the body.

On neuropathological examination the skull and dura were normal. The brain weighted 1250 gms. The brain was large, well-developed and the surfaces appeared healthy. All lobes were of good size and the convolutions appeared strikingly normal in size and pattern. The right cerebellar hemisphere was smaller than the left with irregular small folia in the vermian and paravermian regions. [The discrepancy between the patient's clinical state and the normal gross appearance of the cerebrum was so striking as to suggest that the brain being examined was not that of the patient. It was verified that the proper brain was being examined.]

Coronal sections at $1 \mathrm{~cm}$ intervals revealed that the hippocampus was half the normal size bilaterally over much of its anterior-posterior extent. The rest of the cerebrum appeared normal. The cerebral arteries were normal. The olfactory bulbs were intact. There was no gyral dysplasia. Status marmoratus was not present. The globus pallidus on each side was normal. The temporal lobes except for the hippocampus were of good size and the gyri were full. The ventricles were not enlarged.

Sectioning the brainstem revealed old infarcts in the posterior watershed regions of both cerebellar hemispheres and the adjoining vermis. The bulk of the cerebellum was reduced by about one fifth. The brainstem was normal. The cranial nerves were intact.

On microscopic examination the hippocampus was small bilaterally with gliosis and loss of neurons especially in Sommer's sector. The regions of cerebellar infarction showed loss of superficial folia and replacement with a glial network. There were no signs of active healing and the lesions were obviously old. Microscopic examination of sections from many regions of the cerebral cortex and thalamus revealed no abnormality.

\section{DISCUSSION}

The lesions of the hippocampi are consistent with an episode of acute anoxia. In acute cerebral ischemia due to circulatory failure, infarction in the watershed territories of the cerebral hemispheres would be more likely but the rule is not absolute. The cerebellar lesions were interpreted as watershed in type. Cerebral anoxia associated with epileptic seizures is another possibility, especially in light of the history of a seizure several days before admission. None occurred after admission. Hypoglycemia is unlikely. The term anoxic-ischemia is probably appropriate for the lesions of both the hippocampi and the cerebellum. Presumably the event occurred in the perinatal period. No other pathological process was detected.

The history of the development of the patient's illness is lacking. A sibling probably had a similar illness, suggesting an inherited process. Sections from the cerebral cortex and thalamus showed no evidence of a metabolic disorder, but only routine stains were used.

Discounting these not inconsiderable deficiencies, the case is so striking clinically and pathologically that a detailed analysis is warranted. Assuming that the failure to develop mental and motor function is related to the anoxic-ischemic lesions of the hippocampus and cerebellum, it would be the lesions of the hippocampi that stand incriminated rather than those of the cerebellum. Cerebellar insult is not associated with cerebral devastation of such severity, either clinically or experimentally.

The hippocampus on the other hand, in its role as the seat of memory, plays an essential part in cerebral function. In adults, hippocampal lesions cause a persisting inability to form new memories while pre-insult cognitive function remains largely intact and motor function is preserved. But what would be the effect of permanent hippocampal damage if it occurred perinatally when integrated motor and sensory experience is primitive? If there is no past experience to be retained, cerebral function would remain in abeyance permanently, except for primitive movements.

There is another implication of this line of speculation. The patient showed absence not only of mental development but also of motor activity which remained almost nil. It could be inferred that hippocampal function participates in learned motor activity, even in the newborn. The inference could be drawn that hippocampal function participates crucially in all sensory and motor activity. Its prominent role in the cerebral function termed memory, obscures the more generalized participation of the hippocampus in all cortical activity.

Relevant here is the study of DeLong and Heinz ${ }^{1}$ demonstrating that bilateral hippocampal sclerosis associated with intractable temporal seizures in four young children aged 30, 36, 6 and 23 months, resulted in permanent failure to attain language, complex social interaction and normal child activities. Two children, whose speech had developed normally before the onset of seizures, permanently lost that speech. Eight similar patients were excluded because of incomplete data. The authors concluded that focus on memory as the function of the hippocampus in adults, overlooks its role in the acquisition of language in young children. A broadening of current tenets regarding hippocampal function was recommended.

\section{Further speculation}

The observation that the brain in the present case was strikingly normal in size, indicates that growth and development of the soma and the brain parenchyma proceed normally in the absence of integrated neural function of the individual parts.

If the suggestion that motor learning requires hippocampal participation is valid, some temporary loss of a very recently learned motor skill should occur in acute amnesia. This could be investigated in transient global amnesia where a recently acquired skill might become transiently impaired.

If hippocampal activity participates in every motor and mental transaction, speculation might be carried further. Judging from one's flow of thoughts, cerebral nervous system activity "appears" to be intermittent with three or four thoughts occurring per second. If four thoughts or "bytes" of organized neural activity occur per second, during waking hours, day in and day 
out, continuously for a lifetime, the number of "bytes" would total approximately eight billion at the most. Conceivably, this is within the capacity of the human nervous system, considering that only an infinitesimal amount of higher brain activity can be recalled. Memory would again be the obvious aspect of a generalized hippocampal activity. In this view, experience is recorded as a continuous, longitudinal, neural activity. With repetition of "bytes" over time, the number of associations is increased and memory is strengthened. Current ideas about memory recording, storage, consolidation and retrieval would require revisiting. How constant hippocampal activity participates in every coordinated cerebral sweep corresponding to a thought or action is obscure.

The preceding theorizing is based on the premise that the patient's state was directly related to the hippocampal lesions. Further experience is necessary.

\section{REFERENCE}

1. DeLong GR, Heinz ER. The clinical syndrome of early-life bilateral hippocampal sclerosis. Ann Neurol 1997;42:11-17. 